\title{
“If EQuity's In, We'RE OUT”: SCOPE For FAIRNESS In The NEXT GLOBAL
}

\section{Climate Agreement}

Jonathan Pickering, ${ }^{1}$ Steve Vanderheiden, ${ }^{2}$ and Seumas Miller $^{3}$

Forthcoming in Ethics and International Affairs - please cite published version

\begin{abstract}
At the United Nations climate change conference in 2011, parties decided to launch the "Durban Platform" to work towards a new long-term climate agreement. The decision was notable for the absence of any reference to "equity", a prominent principle in all previous major climate agreements. Wealthy countries resisted the inclusion of equity on the grounds that the term had become too closely yoked to developing countries' favored conception of equity. This conception, according to wealthy countries, exempts developing countries from making commitments that are stringent enough for the collective effort needed to avoid dangerous climate change. In circumstances where even mentioning the term equity has become problematic, a critical question is whether scope for a fair agreement is being squeezed out of negotiations. To address this question we set out a conceptual framework for normative theorizing about fairness in international negotiations, accompanied by a set of minimal standards of fairness and plausible feasibility constraints for sharing the global climate change mitigation effort. We argue that a fair and feasible agreement may be reached by (i) reforming
\end{abstract}

\footnotetext{
${ }^{1}$ PhD candidate, Australian National University. Corresponding author: jonathan.pickering@ anu.edu.au.

${ }^{2}$ Associate Professor of political science and environmental studies, University of Colorado at Boulder; Professorial Fellow, Centre for Applied Philosophy and Public Ethics (CAPPE), an Australian Research Council Special Research Centre, Charles Sturt University, Canberra, Australia.

${ }^{3}$ Foundation Professor of Philosophy, Charles Sturt University; Professorial Research Fellow at CAPPE and at 3TU Centre for Ethics and Technology, Delft University of Technology.
} 
the current binary approach to differentiating developed and developing country groups, in tandem with (ii) introducing a more principled approach to differentiating the mitigation commitments of individual countries. These two priorities may provide the basis for a principled bargain between developed and developing countries that safeguards the opportunity to avoid dangerous climate change without sacrificing widely acceptable conceptions of equity.

\section{ACKNOWLEDGMENTS}

The authors wish to thank the following individuals and groups for helpful feedback: Christian Barry, Simon Caney, Frank Jotzo, Holly Lawford-Smith, Benito Müller, Lavanya Rajamani, Dominic Roser and Henry Shue; participants at a Social and Political Theory seminar at the Australian National University in 2009 (where we presented an earlier working paper that informed the present article) and a workshop on climate justice at the University of Oxford in June 2012; and anonymous reviewers of the manuscript for Ethics and International Affairs. 


\section{INTRODUCTION}

In the final hours of the United Nations climate change conference held in Durban, South Africa, in late 2011, senior negotiators from wealthy and developing countries clustered in a widely reported "huddle" to resolve outstanding points of discord on how to launch negotiations for a long-term global climate agreement to succeed the Kyoto Protocol. Among the statements voiced in the huddle, one of the most intriguing was attributed to the lead United States negotiator, Todd Stern: "If equity's in, we're out."1 In other words, if the resulting decision contained any references to the term "equity," the United States would refuse to participate. As it transpired, the United States and like-minded countries succeeded on this point. The agreed upon Durban Platform for Enhanced Action contained no references either to equity or to the "common but differentiated responsibilities" of all parties for protecting the climate system. ${ }^{2}$ These omissions were notable since both are core principles of the United Nations Framework Convention on Climate Change (UNFCCC, Article 3.1), under whose auspices these negotiations took place.

The debate about equity at Durban is the latest turn in a long-standing dispute between developed and developing countries on how principles of equity or fairness should apply to

\footnotetext{
${ }^{1}$ United States Department of State, “United Nations Climate Change Conference in Durban, South Africa, Special Briefing: Todd Stern, Special Envoy for Climate Change" (Department of State, December 13, 2011); www.state.gov/r/pa/prs/ps/2011/12/178699.htm; accessed September 6, 2012. In response to a question about the wording of his quotation, Stern stated, "Whether I said those exact words, I have no idea. I might have, but ... that's certainly the idea."

${ }^{2}$ UNFCCC, "Establishment of an Ad Hoc Working Group on the Durban Platform for Enhanced Action" (2011); unfccc.int/bodies/body/6645.php.
} 
differentiating each group's respective contributions to reducing or limiting ("mitigating") global greenhouse gas emissions. The U.S. position voiced at Durban is consistent with its long-held view that any global climate agreement must include all "major emitters," which now notably includes developing countries, such as China and India, in addition to developed countries. Developing countries for their part have persistently argued that since the convention links equity to wealthy countries' responsibility to "take the lead" in addressing climate change (Article 3.1), this implies that developing countries should not be required to take on equivalent commitments.

What is new is that whereas the United States had been willing previously to countenance differing interpretations of equity, it now seems to see the term as so closely yoked to the conception of equity favored by developing countries that it has become an obstacle to agreement. As Lavanya Rajamani observes, "the fact that the divisions on the application of this principle are such as to preclude even a rote invocation of it signals a likely recasting of differentiation in the future climate regime." ${ }^{3}$ Rajamani cautions about the implications of this trend:

While the international regime can survive the erosion of certain limited forms of differential treatment, a wholesale rejection of differential treatment, and of the

\footnotetext{
${ }^{3}$ Lavanya Rajamani, "The Changing Fortunes of Differential Treatment in the Evolution of International Environmental Law,” International Affairs 88, no. 3 (2012), p. 618.
} 
"equity" concerns that animate it, would destabilize the normative core of the regime. ${ }^{4}$

In these circumstances it is critical to assess what scope exists for achieving a fair agreement within the time frame mapped out under the Durban Platform, which aims to conclude no later than 2015 a "protocol, another legal instrument or an agreed outcome with legal force" that would be implemented from 2020 (paragraph 4).

The remainder of this article begins by setting out a conceptual framework for normative theorizing about fairness in international negotiations, with a particular emphasis on the role of feasibility considerations. We then outline a set of minimum fairness standards and feasibility constraints that should be taken into account in developing proposals for reforming differentiation under the multilateral climate regime. Based on these considerations, we argue that a fair and feasible agreement will require reforming the current dichotomy between developed and developing countries' commitments, coupled with a more principled approach to differentiating the level of national mitigation efforts. In the final section of the article we illustrate how these reforms could form the basis of a principled bargain between developed and developing countries. ${ }^{5}$

\footnotetext{
${ }^{4}$ Ibid., pp. 616-17.

${ }^{5}$ This article builds on an earlier working paper: Jonathan Pickering, Steve Vanderheiden, and Seumas Miller. "Ethical Issues in the United Nations Climate Negotiations: A Preliminary Analysis of Parties' Positions" (Canberra: Centre for Applied Philosophy and Public Ethics (CAPPE), 2009).
} 


\section{EfFectiveness, Fairness, AND Feasibility in Climate Negotiations: ConCEPTS AND}

\section{METHODS}

Fairness represents one of several possible criteria for evaluating proposals and outcomes in climate ethics and policy, along with such others as environmental effectiveness, costeffectiveness, and institutional feasibility. ${ }^{6}$ All of these criteria are scalar rather than purely binary in nature-in the sense that an agreement could be more or less feasible, more or less fair, and so on-and it is common to frame negotiations as a process of making trade-offs among these criteria. However, the quotation with which we commenced the article raises the prospect that there may be some fundamental incompatibility between certain criteria. In order to investigate this concern, we progressively introduce a set of seven constraints that we believe a future climate agreement should meet if it is to be minimally effective, fair, and feasible. In doing so we recognize that trade-offs may be necessary in order to satisfy maximal accounts of certain criteria, but first we wish to ascertain if an effective agreement could be feasible without thereby sacrificing minimal standards of fairness.

\section{Effectiveness}

We will assume that in order to meet a plausible standard of environmental effectiveness, the global climate regime must aim to meet at a minimum the international pledge to "hold the

\footnotetext{
${ }^{6}$ S. Gupta et al., "Policies, Instruments and Co-operative Arrangements," in Climate Change 2007: Mitigation, Contribution of Working Group III to the Fourth Assessment Report of the Intergovernmental Panel on Climate Change (Cambridge and New York: Cambridge University Press, 2007), p. 751.
} 
increase in global temperature below two degrees Celsius." ${ }^{, 7}$ Scientists and policy-makers have now widely recognized that this requires holding cumulative emissions within a finite intergenerational "budget" for the foreseeable future. ${ }^{8}$ We assume further that over the next few decades the primary means of pursuing the temperature goal will be conventional mitigation (for example, through shifting to low-emitting energy production) rather than employing geoengineering technologies, which remain largely untested and controversial for their potential side effects.

Given the dispersion of polluting activities across the world's major economies, adequate mitigation cannot be achieved by any one state alone. Since mitigation involves substantial present costs to individual states while providing a more general global benefit over the longer term (in the form of a safer climate), there is a risk that countries will seek to free-ride on the efforts of others, thus undermining the overall effectiveness of mitigation efforts. Multilateral agreement is therefore necessary to provide restraints on free-riding. Due to the rapid observed and projected rise in the share of global emissions in developing countries and the limited availability of low-cost mitigation options in developed countries, action by developed countries alone will be insufficient to avoid dangerous climate change. ${ }^{9}$ Substantial mitigation could be achieved in principle through coordinated action by a smaller number of major emitters (such as the G20), although such an arrangement may not adequately protect smaller emitters vulnerable

\footnotetext{
${ }^{7}$ Copenhagen Accord (2009), para. 1.

${ }^{8}$ Henry Shue, "Human Rights, Climate Change, and the Trillionth Ton," in Denis G. Arnold, ed., The Ethics of Global Climate Change (Cambridge: Cambridge University Press, 2011).

${ }^{9}$ Gupta et al., "Policies, Instruments and Co-operative Arrangements,” p. 776.
} 
even to moderate levels of climate change. ${ }^{10}$ Nevertheless, the argument we advance here could apply to a multilateral agreement whether or not its membership were universal. These considerations lead us to the first of our constraints:

1. Effectiveness. A global response to climate change will be effective only if it includes a multilateral agreement entailing substantial mitigation efforts within a critical mass of major developed and developing economies.

It is important to underscore that this constraint posits multilateral agreement as a necessary but insufficient condition for avoiding dangerous climate change. It is therefore compatible with the view that responding to climate change requires a "polycentric" approach encompassing national and subnational policy reforms, private sector innovation, and action by citizens and consumers. ${ }^{11}$ A polycentric approach combined with a multilateral agreement could conceivably secure an adequate level of mitigation even if one major economy (the most obvious potential holdout at present being the United States) does not sign on to the agreement. The constraint is also consistent with the widespread assessment that ambitious action on mitigation will need to commence well before 2020 if excessively high stabilization costs are to be avoided. ${ }^{12}$ Finally, as

\footnotetext{
${ }^{10}$ Robyn Eckersley, “Moving Forward in Climate Negotiations: Multilateralism or Minilateralism?” Global Environmental Politics 12, no. 2 (2012).

${ }^{11}$ Elinor Ostrom, "Polycentric Systems for Coping with Collective Action and Global Environmental Change," Global Environmental Change 20, no. 4 (2010).

${ }^{12}$ M. Meinshausen et al., "Greenhouse-Gas Emission Targets for Limiting Global Warming to $2{ }^{\circ} \mathrm{C}, ”$ Nature 458 (2009).
} 
elaborated below, the constraint does not make any assumptions about the distribution of mitigation costs among countries. The constraint simply emphasizes that without a critical mass of participants cooperating under a multilateral agreement, the global response to climate change will be ineffective.

\section{Fairness}

We take the concept of fairness to denote a criterion of evenhanded, impartial, or nonarbitrary treatment of persons and groups in the distribution of benefits (or goods) and burdens. ${ }^{13}$ Consistent with the practice of many parties to climate negotiations and the usage in recent literature, we will use the terms "fairness" and "equity" interchangeably as broader moral and political concepts applicable to negotiations, while recognizing that equity also has specific legal connotations under the convention. ${ }^{14}$ Both fairness and equity may apply to the substantive distribution of goods as well as procedures for distribution; here we focus primarily on the substantive aspect. Research on fairness in climate negotiations may evaluate policy options on the basis of their compatibility with both (1) independent standards of fairness as well as (2) conceptions of fairness that actors may either be committed to or invoke for strategic reasons. In subsequent sections we outline constraints relating to each of these aspects.

\footnotetext{
${ }^{13}$ Compare John Rawls, A Theory of Justice, rev. ed. (Cambridge, Mass.: Harvard University Press, 1999), p. 5.

${ }^{14}$ See, e.g., Friedrich Soltau, Fairness in International Climate Change Law and Policy (New York: Cambridge University Press, 2009 ), pp. 3-4.
} 


\section{Feasibility}

The term "feasibility," as commonly employed in political theory, comprises dimensions of accessibility (the existence of a practical route from one state of affairs to another) and stability (whether the proposed state of affairs can be maintained once it is reached). ${ }^{15}$ If we are concerned about fairness, we will have good reason to be concerned about feasibility, since an arrangement that is fair but unfeasible may result in the persistence of an unfair status quo. A considerable amount of research in the field of climate ethics already incorporates some realworld constraints, such as partial (rather than full) compliance of actors with moral requirements. ${ }^{16}$ Nevertheless, a key limitation of many proposals for fairly distributing the benefits and burdens of mitigation—both in climate ethics and climate economics—is a tendency to pay limited attention to their feasibility. Accordingly, if research is to heed a recent call for "climate ethics for climate action," it must incorporate feasibility considerations more systematically. ${ }^{17}$

Whereas the accessibility dimension of feasibility is arguably less relevant at the stage of formulating core normative principles, it is central to theorizing strategies for political reform. ${ }^{18}$ Formulating an appropriate conception of accessibility is particularly important in policy

\footnotetext{
${ }^{15}$ Pablo Gilabert and Holly Lawford-Smith, "Political Feasibility: A Conceptual Exploration,” Political Studies (forthcoming), p. 3.

${ }^{16}$ A recent example in this journal is Henry Shue, "Face Reality? After You!-A Call for Leadership on Climate Change,” Ethics \& International Affairs 25, no. 1 (2011).

${ }^{17}$ Andrew Light, "Climate Ethics for Climate Action," in David Schmidtz and Elizabeth Willott, eds., Environmental Ethics: What Really Matters? What Really Works? (Oxford: Oxford University Press, 2011).

${ }^{18}$ Gilabert and Lawford-Smith, "Political Feasibility,” pp. 11-12.
} 
contexts with long time horizons, such as climate change. As Pablo Gilabert and Holly LawfordSmith observe: "What may have very low accessibility now may turn out to be highly accessible in the future, given a sufficiently long sequence of dynamic expansions of the feasible sets of political reform."19 Taking this perspective can help us avoid the twin pitfalls of (1) the overly pessimistic view that a policy will never be feasible simply because it is not feasible now and (2) the overly optimistic view that a policy that may be feasible at some point in time is feasible now and will remain so.

An important intersection between fairness and feasibility arises once we take account of the fact that any global agreement must rely on the voluntary participation of states. There is a widely observed empirical link between the perceived fairness of an international agreement among parties and its likelihood of being adopted and complied with. ${ }^{20}$ When combined with effectiveness, this provides the basis for an initial feasibility constraint:

2. Perceived fairness. An effective multilateral climate agreement will be feasible only if it is accepted as fair by all parties whose participation is necessary to satisfy effectiveness.

Once conceptions of fairness are incorporated into a normative account, two reductive challenges must be addressed. The first is that parties' conceptions of fairness are ultimately reducible to

\footnotetext{
${ }^{19}$ Ibid., p. 13.

${ }^{20}$ Scott Barrett, Environment and Statecraft: The Strategy of Environmental Treaty-Making (Oxford: Oxford University Press, 2003), p. xiv.
} 
parties' calculations of material interests. On this view, commonly associated with realist theories of international relations, moral argument is of little or no consequence in affecting the substantive outcome of negotiations. This empirical account lends support to normative claims that any agreement should satisfy an international version of the Pareto principle, whereby no state loses more than it gains from participating. ${ }^{21}$ Granted, some evidence suggests that parties to climate negotiations largely choose principles of fairness that match their own interests most closely. ${ }^{22}$ However, a growing body of literature based on constructivist theories suggests that ethical arguments and norms may influence international relations-on issues ranging from the end of colonialism to prohibitions on certain types of weaponry-not least by shaping the way in which different countries perceive their own interests. ${ }^{23}$ Thus, conceptions of fairness and moral arguments may play both an enabling and a constraining role in influencing what is feasible in negotiations.

A second reductive argument posits that the fairness of an agreement should be judged solely according to what parties perceive to be fair. But even where negotiations are conducted under procedurally fair conditions, it is conceivable that the resulting distribution of benefits and burdens could be unfair from the perspective of plausible normative theories, or that parties may need to choose among several mutually acceptable settlements, some of which may be fairer than

\footnotetext{
${ }^{21}$ As exemplified by Eric A. Posner and David Weisbach, Climate Change Justice (Princeton, N.J.: Princeton University Press, 2010).

${ }^{22}$ Andreas Lange et al., "On the Self-interested Use of Equity in International Climate Negotiations,” European Economic Review 54, no. 3 (2010).

${ }^{23}$ Compare Christian Reus-Smit and Duncan Snidal, "Reuniting Ethics and Social Science: The Oxford Handbook of International Relations," Ethics \& International Affairs 22, no. 3 (2008).
} 
others. ${ }^{24}$ Reference to independent standards of fairness is therefore important for ethical analysis of international negotiations. In order to provide action-guiding recommendations such standards should be applied to the set of feasible agreements, which will be circumscribed by what parties could plausibly be persuaded to consider as fair. ${ }^{25}$ The independent standard need not correspond to a single theoretical conception of fairness, but (as we illustrate below) could represent a minimal standard incorporating common elements of robust theories of fairness.

\section{Differentiation in Climate Negotiations: Key Issues AND CONSTRAinTS}

With this conceptual framework in place, we now focus on the question of how a fair and feasible agreement may be reached regarding the differentiation of mitigation efforts among countries. First we distinguish two types of differentiation, then we introduce several further constraints that apply specifically to fairness and feasibility in differentiation.

\section{Categorical and National Differentiation}

We use the term "differentiation" in a broad sense to encompass the idea of "differential treatment" ("the use of norms that provide different, presumably more advantageous, treatment to some states") as well as norms that may require more stringent actions by some states. ${ }^{26}$ In the remainder of the article we distinguish two types of differentiation that are particularly relevant

\footnotetext{
${ }^{24}$ Compare Cecilia Albin, Justice and Fairness in International Negotiation (Cambridge and New York: Cambridge University Press, 2001).

${ }^{25}$ See Adam Swift, "The Value of Philosophy in Nonideal Circumstances," Social Theory and Practice 34, no. 3 (2008), p. 369.

${ }^{26}$ Lavanya Rajamani, Differential Treatment in International Environmental Law (Oxford: Oxford University Press, 2006$)$, p. 1.
} 
to climate negotiations. The first type relates to how groups of countries are delineated ("categorical differentiation"), while the second concerns the way in which national levels of commitment are set within individual groups ("national differentiation").

To place the Durban debate on equity in context, we provide some brief background on how each type of differentiation has evolved in previous climate agreements. Categorical differentiation reached its high point in the Kyoto Protocol (adopted in 1997), which required only developed countries to meet legally binding emissions limitations. ${ }^{27}$ The protocol also included a degree of national differentiation among developed countries' targets, albeit one that emerged through a largely ad hoc approach. ${ }^{28}$

In tandem with growing recognition that maintaining a safe limit on temperature rise requires substantial mitigation in developing countries, the last decade has seen a progressive erosion of formerly prominent aspects of categorical differentiation. ${ }^{29}$ In particular, outcomes of recent negotiations, including the 2009 Copenhagen Accord and the 2010 Cancún Agreements, include not only "commitments" by developed countries but also "actions" by developing countries on mitigation. The Copenhagen Accord also introduced a far more flexible form of national differentiation than under the protocol, whereby each country could make political pledges (rather than legally binding commitments) whose form and extent could be determined unilaterally.

\footnotetext{
${ }^{27}$ Rajamani, “The Changing Fortunes of Differential Treatment,” pp. 605-606.

${ }^{28}$ Harald Winkler, Bernd Brouns, and Sivan Kartha, "Future Mitigation Commitments: Differentiating Among non-Annex I Countries," Climate Policy 5, no. 5 (2006), p. 475.

${ }^{29}$ Rajamani, “The Changing Fortunes of Differential Treatment,” p. 616. 
The absence of the term "equity" from the Durban Platform appears to rule out at the very least a rigid Kyoto-style form of categorical differentiation. Nevertheless, the decision allows considerable leeway for an approach lying anywhere between the current level of differentiation and much greater symmetry between developed and developing countries' commitments than at present. Moreover, in specifying that the agreement will be "under the Convention," the Durban Platform implicitly imports key principles from the convention, including equity and common but differentiated responsibilities. ${ }^{30}$

\section{Minimal Standards of Fairness in Differentiation}

A starting point for a minimal independent standard of fairness would be to require that any form of differentiation should reflect (implicitly or explicitly) moral principles widely accepted in climate ethics as relevant to distributing the costs and benefits of addressing climate change. Among prevailing approaches in climate ethics one may draw a broad distinction between those that focus on how to allocate national efforts contributing to global mitigation ("effort-sharing approaches") and those that focus on how to distribute global atmospheric resources ("resourcesharing approaches"). ${ }^{31}$ Effort-sharing approaches most frequently invoke principles of (1) contribution to the problem (through proportional contribution to cumulative or current

\footnotetext{
${ }^{30}$ Ibid., p. 618.

${ }^{31}$ BASIC Experts, "Equitable Access to Sustainable Development: Contribution to the Body of Scientific Knowledge" (Beijing, Brasilia, Cape Town, and Mumbai: BASIC Expert group, 2011), pp. 9-11.
} 
greenhouse gas emissions) and (2) capacity to pay (for domestic or international mitigation). ${ }^{32}$ Somewhat less widely accepted but still commonly invoked is (3) the benefit that current generations have inherited from centuries of emissions-intensive economic development. ${ }^{33}$ Resource-sharing approaches most commonly invoke the principle that each person should have an equal per capita entitlement to a share of Earth's capacity to absorb emissions. ${ }^{34}$

We have discussed the relative merits of some of these approaches elsewhere, ${ }^{35}$ but for present purposes we formulate a minimal standard of fairness that captures core elements of the most widely discussed allocation methods:

3. Fairness. A climate agreement is minimally fair only if: (1) each actor's mitigation efforts are proportional to its responsibility for present and/or past emissions and capacity to pay for mitigation, and/or (2) it facilitates the progressive global convergence of per capita emissions toward a cumulative limit compatible with avoidance of dangerous climate change.

\footnotetext{
${ }^{32}$ See Simon Caney, "Climate Change and the Duties of the Advantaged," Critical Review of International Social and Political Philosophy 13, no. 1 (2010).

${ }^{33}$ See, e.g., Henry Shue, “Global Environment and International Inequality,” International Affairs 75, no. 3 (1999).

${ }^{34}$ See, e.g., Peter Singer, One World: The Ethics of Globalization (Melbourne: Text, 2002).

${ }^{35}$ See, e.g., Steve Vanderheiden, Atmospheric Justice: A Political Theory of Climate Change (New York: Oxford University Press, 2008).
} 
Note that this criterion, while broad, already rules out certain distributive approaches, such as those based on equal per capita sharing of costs or grandfathering of existing emission levels, both of which tend to favor wealthy high-emitting countries. At the same time, while this approach requires a substantial degree of national differentiation, it is indifferent as to whether any form of categorical differentiation is used. Further fairness constraints could be specified (particularly requirements for fairness in adaptation), but this should be sufficient for illustrating our general approach to differentiating mitigation efforts.

\section{Feasibility Constraints: Plural Conceptions of Fairness and Institutional Inertia}

We may now introduce several further feasibility constraints that must be met if fair differentiation is to be achievable under a post-2020 climate agreement. Each could be said to represent a conception of fairness strongly held by some or all negotiating groups, thus fleshing out the more general constraint of perceived fairness. Here we select from a set of feasibility constraints specified by Valentina Bosetti and Jeffrey Frankel based on their analysis of recent negotiations: ${ }^{36}$

4. Participation. "The United States will not commit to quantitative targets unless

China and other major developing countries commit to quantitative targets at the same time."

\footnotetext{
${ }^{36}$ Valentina Bosetti and Jeffrey Frankel, "Politically Feasible Emissions Targets to Attain 460 ppm $\mathrm{CO}_{2}$ Concentrations," Review of Environmental Economics and Policy 6, no. 1 (2012), pp. 89-90. The numbering and titles are our own.
} 
5. Basis for differentiation. "China, India, and other developing countries will not make sacrifices they view as a. fully contemporaneous with rich countries, b. different in character from those made in the past by richer countries, c. preventing them from industrializing, $d$. failing to recognize that richer countries should be prepared to make greater economic sacrifices to address the problem than poorer countries, or e. failing to recognize that the rich countries have benefited from an unfair advantage in being allowed to achieve levels of per capita emissions that are far above those of the poor countries."

6. Costs. "No country will accept a path of targets that is expected to cost it more than Y percent of income [set at 1 percent by Bosetti and Frankel] throughout the twenty-first century (in present discounted value)."

While participation appears to permit unfairness if one takes the view that the United States ultimately has a responsibility to act unconditionally, the participation of major developing countries is nevertheless a corollary of the effectiveness constraint outlined above. Moreover, participation does not stipulate that developing countries should pay for all their domestic emissions reductions themselves (since they could be financed by developed countries), although equally the costs criterion implies that it would be implausible to expect developed countries to bear all the costs of global mitigation. One could also argue that costs would permit an unfair agreement since countries may have a responsibility to remedy harm regardless of the cost to themselves. However, given the voluntary nature of participation in a global agreement it is 
highly unlikely that countries would inflict very large economic costs on themselves in the absence of international legal liability to do so.

We introduce one final feasibility constraint not included by Bosetti and Frankel, based on the idea of institutional inertia in the multilateral climate regime:

7. Institutional compatibility. A medium-term climate agreement will be feasible only if it maintains a sufficient degree of compatibility with deeply embedded institutional elements of the climate regime.

Including this constraint may seem controversial given the numerous challenges that the UNFCCC has faced in recent years, ranging from efforts by the United States and others to construct alternative bodies for addressing climate change among a smaller group of parties, to the near collapse of the multilateral process in Copenhagen. Yet the UNFCCC has demonstrated a significant degree of resilience as "minilateral" initiatives, such as the Asia-Pacific Partnership on Clean Development and Climate, have fallen by the wayside, while at Cancún in 2010 parties reaffirmed their willingness to invest in the multilateral process. ${ }^{37}$ At the same time, numerous commentators have highlighted the difficulties of enacting thoroughgoing reform of the

\footnotetext{
${ }^{37}$ See Eckersley, "Moving Forward in Climate Negotiations”; and Michael Grubb, "Cancún: The Art of the Possible," Climate Policy 11, no. 2 (2011)
} 
UNFCCC. ${ }^{38}$ One reason for the difficulty of institutional change in the UNFCCC is the prevailing consensus-based decision-making procedure, which itself has proved resistant to reform. Certain kinds of institutional dysfunction should not be taken as given but rather as the object of reform proposals themselves. Nevertheless, there are some entrenched features of the climate regime whose reform or abolition would arguably require an implausibly large amount of political will to enact in the foreseeable future. In the next section we discuss one institutional feature widely considered to be deeply embedded-namely, the categorization of developed and developing countries into formal groupings.

Finally, we note another possible feasibility consideration relevant to the Durban debate on equity—namely, the prospect that parties could simply reject as unfair approaches that are couched in certain terms. Arguably terms such as "climate debt" constitute rhetorical constraints due to the connotations of blame they hold for developed countries. ${ }^{39}$ However, Stern's response to a question about what he meant by "If equity's in, we're out" is noteworthy:

It's not that there's anything wrong with ... talking about equity in the context of climate negotiations, and the term appears in the framework convention, and we tend to look at the phrase as calling for fairness to all parties, and we think that's fine.

\footnotetext{
${ }^{38}$ See, e.g., Joanna Depledge, “The Opposite of Learning: Ossification in the Climate Change Regime,” Global Environmental Politics 6, no. 1 (2006).

${ }^{39}$ See Jonathan Pickering and Christian Barry, "On the Concept of Climate Debt: Its Moral and Political Value," Critical Review of International Social and Political Philosophy (forthcoming).
} 
But in this context, when we're talking about setting up a negotiation, ... the key element of which for us, was to include all the major players in the same legal system kind of together, we just thought that that would be a distraction that would tend to drive people back into the old paradigm, if you will, and we didn't want to go there. ${ }^{40}$

This, coupled with the reference to the convention mentioned above, suggests that it would be premature to see the lack of reference to equity in the Durban Platform as conclusive evidence for a rhetorical constraint on explicit reference to equity in a future agreement, let alone on giving that principle substantive effect.

\section{Priorities FOR ReFORMING DifFERENTIATION}

\section{Categorical Differentiation: The Need to Reform the Annex System}

The divide between developing and developed countries that is characteristic of many areas of international negotiation has become especially entrenched in the climate regime as a result of the structure of the convention, which divides countries into Annexes according to whether they are developed (roughly equivalent to Annex I) or developing (non-Annex I). ${ }^{41}$ Non-Annex I countries may voluntarily move to Annex I, but few have done so to date, largely owing to

\footnotetext{
${ }^{40}$ United States Department of State, "United Nations Climate Change Conference in Durban, South Africa."

${ }^{41}$ Depledge, "The Opposite of Learning," p. 9.
} 
procedural hurdles as well as limited incentives to take on binding commitments. ${ }^{42}$ While some countries have recently challenged current approaches to country groupings, most non-Annex I countries have resisted what they see as efforts to undermine a "firewall" that safeguards Kyotostyle categorical differentiation. ${ }^{43}$

There are strong reasons for seeing the current approach to country listings as seriously flawed. Even if differentiation by listing may aim to capture some of the essence of the principle of common but differentiated responsibilities, a binary distinction is a crude way of doing so. Moreover, it is clear that the distinction between developed and developing countries is not tied reliably to objective criteria. For example, a number of non-Annex I countries—notably such countries as Singapore, Qatar, and Saudi Arabia—have higher per capita incomes or emissions than many Annex I countries. ${ }^{44}$ As a result, some countries that should be taking on a greater share of the global mitigation and financing effort by virtue of their national circumstances remain unfairly exempt from comparable commitments.

Arguably an even more serious problem for effective global mitigation is the lack of distinction among countries still properly classed as "developing." Although the convention requires special treatment for certain groups of developing countries on the basis of their poverty or vulnerability to climate change, there is no clear distinction between (1) large and

\footnotetext{
${ }^{42}$ Joanna Depledge, “The Road Less Travelled: Difficulties in Moving Between Annexes in the Climate Change Regime," Climate Policy 9 (2009).

${ }^{43}$ Lavanya Rajamani, “The Making and Unmaking of the Copenhagen Accord," International \& Comparative Law Quarterly 59, no. 3 (2010), pp. 831-32.

${ }^{44}$ Australia, "Mitigation: Submission to the AWG-LCA and the AWG-KP (24 November 2008)" (Bonn: UNFCCC, 2008).
} 
economically advanced developing economies and (2) a diverse range of smaller, lower-emitting developing countries. This is despite the fact that major developing economies have increasingly coordinated their positions in negotiations, particularly the BASIC group (Brazil, South Africa, India, and China), and have often found themselves at odds with vulnerable countries seeking more ambitious action on mitigation.

Is the solution to dispense with the Annex system altogether? Numerous proposals in climate ethics and policy, for example, adopt approaches based purely on national rather than categorical differentiation by using a sliding scale applicable to all countries. ${ }^{45}$ This approach may offer greater theoretical robustness but encounters two major feasibility concerns. First, there may be good reasons to distinguish some countries' commitments according to qualitative or non-scalar features, such as their legal stringency, or the scope of their emissions measurement and reporting obligations. Second, the Annex system is arguably so entrenched that it could be described without exaggeration as "the political and procedural cornerstone of the climate change regime. ${ }^{" 46}$ Accordingly, eradicating it altogether would divert scarce political will that could better be applied to other reform priorities. Instead, the preferable avenue would be to focus on ways to modify the Annex system so as to address its critical deficiencies.

\footnotetext{
${ }^{45}$ See, e.g., Paul Baer et al., “Greenhouse Development Rights: Towards an Equitable Framework for Global Climate Policy,” Cambridge Review of International Affairs 21, no. 4 (2008).

${ }^{46}$ Depledge, “The Road Less Travelled," p. 273.
} 


\section{National Differentiation: The Case for a Principled Approach}

The minimal fairness standard outlined above requires that national mitigation efforts must reflect widely accepted principles of fairness, such as responsibility, capacity, and equality. While many developing countries have also argued for a morally principled approach to distributing mitigation efforts, this view appears to be at odds with the position of many developed countries, which (with the notable exception of the European Union) have generally resisted criteria-based approaches. Developed countries have frequently contended that no single approach to fairness could capture the diversity of parties' national circumstances. ${ }^{47}$

An initial appeal of ad hoc approaches is that they appear to respect the diversity of views on effort-sharing and to allow each country to take its national circumstances into account. However, unstructured approaches tend to downplay factors that many parties consider as important, such as the responsibility of countries to prevent and remedy harm to other countries, regardless of whether they would otherwise gain or lose from an agreement. Furthermore, a lack of comparability in ad hoc approaches may exacerbate suspicions among parties that others are free-riding on their actions, as well as allowing unequal bargaining power among countries to operate unchecked. Analysis of the Copenhagen pledges suggests that many developing countries' mitigation pledges are at a level comparable to those of developed countries when measured against their projected "business as usual" emissions level. ${ }^{48}$ Thus, even though the

\footnotetext{
${ }^{47}$ These views were evident in a recent UNFCCC workshop; see UNFCCC, "Workshop on Equitable Access to Sustainable Development (AWG-LCA 15)" (2012); unfccc.int/meetings/bonn_may_2012/workshop/6658.php; accessed September 6, 2012.

${ }^{48}$ Frank Jotzo, "Comparing the Copenhagen Emissions Targets," Crawford School Centre for Climate Economics \& Policy Paper No. 1.10 (2010)
} 
current ad hoc approach may have encouraged greater participation of developing countriesensuring a far wider coverage of global emissions than the Kyoto Protocol-it has arguably failed to encourage developed countries to take on their fair share of the global burden.

Even if a principled approach were desirable, one could still argue that reaching agreement on a common set of principles would be impossible. However, several countervailing arguments could be made. One suggestive response would be to point to formulaic approaches used in other areas of international relations, including UN peacekeeping and ozone protection, and the distribution of the EU's emissions target among its member states. ${ }^{49}$ Nevertheless, the challenge of reconciling multiple conceptions of fairness in climate change mitigation is arguably much greater than in any of these contexts. Not only are the over 190 parties to the convention far more diverse in wealth, institutional composition, and cultural tradition than EU member states, but the economic costs involved are much higher than in any other context where burden-sharing formulae have been adopted. For example, the UN's budget for peacekeeping and regular operations together is around $\$ 10$ billion a year, whereas recent estimates of the incremental investment in mitigation required globally by 2030 range from $\$ 380$ billion to $\$ 1.2$ trillion a year. ${ }^{50}$ For these reasons, arguments from analogy need to be supplemented with a more direct assessment of whether and how major disagreements could be overcome.

\footnotetext{
${ }^{49}$ See Scott Barrett, Why Cooperate? The Incentive to Supply Global Public Goods (Oxford: Oxford University Press, 2007); and Paule Stephenson and Jonathan Boston, "Climate Change, Equity and the Relevance of European 'Effort-sharing' for Global Mitigation Efforts," Climate Policy 10, no. 1 (2010).

${ }^{50}$ See United Nations Peacekeeping: www.un.org/en/peacekeeping/operations/financing.shtml (United Nations, 2011); accessed September 18, 2012; Assessment of Member States' Contributions to the United Nations Regular Budget for 2012, ST/ADM/SER.B/853 (December 27, 2011);
} 
Given highly divergent conceptions of fairness, any principled approach will need to incorporate multiple criteria common or tolerable to the different approaches in order to achieve the requisite level of acceptability. ${ }^{51}$ However, there remains a considerable risk that one country's favored principle cannot be incorporated without thereby violating that of another. The paradigm example of such a dilemma is the question of how responsibility for past emissions should be taken into account. Once historical emissions are included, some allocation methods would require countries, such as the United States, to reduce their emissions to zero or even below zero by $2050 .{ }^{52}$ Developed countries have argued that the investments required to achieve such targets would too massive to secure their citizens' support (thus violating costs).

Developing countries, however, would see a failure to take account of historical responsibility as denying them the right to develop that wealthy countries have enjoyed (thus violating basis for differentiation).

Most work in climate ethics strongly supports explicit consideration of past emissions in determining a country's responsibilities in the belief that countries should be held responsible for avoiding and remedying their contribution to harm. One of us has previously advanced a specific proposal on the treatment of historical responsibility, ${ }^{53}$ but here we limit our discussion to

\footnotetext{
and Susanne Olbrisch, Erik Haites, Matthew Savage, Pradeep Dadhich, and Manish Kumar Shrivastava, "Estimates of Incremental Investment for and Cost of Mitigation Measures in Developing Countries," Climate Policy 11, no. 3 (2011), pp. 970-86, at p. 974.

${ }^{51}$ Madeleine Heyward, "Equity and International Climate Change Negotiations: A Matter of Perspective," Climate Policy 7 (2007).

${ }^{52}$ See, e.g., BASIC Experts, "Equitable Access to Sustainable Development.”

${ }^{53}$ Vanderheiden, Atmospheric Justice.
} 
highlighting two approaches that may help break the impasse on this question, while recognizing that other theories may also be capable of satisfying both fairness and perceived fairness.

First, while some authors suggest that full responsibility for historical emissions could be justified on the grounds that contemporary citizens of developed countries have benefited from historical emissions, others have suggested that historical responsibility may be constrained by considerations of foreseeability and avoidability of harm. ${ }^{54}$ On this basis, as well as on pragmatic grounds of data availability, counting emissions from a date such as 1990 (the date of publication of the first report of the Intergovernmental Panel on Climate Change [IPCC]) may be preferable. ${ }^{55}$ While choosing 1990 rather than 1750 makes a tangible difference to developed and developing countries' share of cumulative emissions, the recent swift rise of global emissions means that pre-1990 emissions will represent an ever smaller proportion of cumulative emissions in coming decades. ${ }^{56}$ Nevertheless, outstanding questions would need to be resolved over whether responsibility should accrue for all post-1990 emissions or only those above a level required for a minimally decent standard of living.

\footnotetext{
${ }^{54}$ Shue, "Global Environment and International Inequality”; contrast Rudolf Schüssler, "Climate Justice: A Question of Historic Responsibility?" Journal of Global Ethics 7, no. 3 (2011); and Seumas Miller, "Collective Responsibility, Epistemic Action and Climate Change," in Nicole A. Vincent, Ibo van de Poel, and Jeroen van den Hoven, eds., Moral Responsibility: Beyond Free Will and Determinism (Heidelberg: Springer, 2011).

${ }^{55}$ See Vanderheiden, Atmospheric Justice, p. 190.

${ }^{56}$ Niklas Höhne et al., “Contributions of Individual Countries' Emissions to Climate Change and Their Uncertainty,” Climatic Change 106, no. 3 (2011); and W. J. W. Botzen, J. M. Gowdy, and J. C. J. M. van den Bergh, "Cumulative $\mathrm{CO}_{2}$ Emissions: Shifting International Responsibilities for Climate Debt," Climate Policy 8 (2008).
} 
Second, historical responsibility could be reflected not solely through the allocation of emissions entitlements but also in the allocation of responsibilities for mobilizing climate finance for developing countries, particularly to support adaptation to the adverse consequences of climate change resulting from past emissions. ${ }^{57}$ Allowing substitution between these types of resources would be consistent with a basic point commonly underscored by theorists that there is no human "right to emit" per se. Rather, emissions are merely an instrumental means of securing such basic rights or goods as health, food, water, and shelter. ${ }^{58}$

Although a substantive agreement on how historical responsibility should be applied will face considerable obstacles, it is notable that the Cancún Agreements explicitly referred to historical responsibility for the first time in a consensus-based UNFCCC decision, which may open up scope for deliberation on this issue. ${ }^{59}$ Disagreement over other substantive principles may likewise be expected to be difficult but not impossible to overcome. The principle of longterm convergence toward equal per capita emissions, for example, has been supported by developed countries, such as EU members, as well as many developing countries. ${ }^{60}$ At present, however, the accessibility of such an approach is limited by the steep transitional costs faced by countries with high or quickly rising per capita emissions, among which are both developed

\footnotetext{
${ }^{57}$ Compare Steve Vanderheiden, “Globalizing Responsibility for Climate Change," Ethics \& International Affairs 25, no. 1 (2011), pp. $81-82$.

${ }^{58}$ Tim Hayward, “Human Rights Versus Emissions Rights: Climate Justice and the Equitable Distribution of Ecological Space,” Ethics \& International Affairs 21, no. 4 (2007).

${ }^{59}$ Grubb, “Cancún: The Art of the Possible,” p. 847.

${ }^{60}$ Compare A. Lange, C. Vogt, and A. Ziegler, "On the Importance of Equity in International Climate Policy: An Empirical Analysis," Energy Economics 29 (2007), p. 547.
} 
countries (such as the United States) and developing countries (such as China). As we outline in the next section, a phased approach to principled allocation could help to resolve this issue.

\section{ToWARd A Principled BARgain}

We now illustrate how the two reform priorities outlined above-improved categorical differentiation through reforming the existing Annex system, and a more principled approach to national differentiation—could be translated into elements of a coherent institutional framework.

The first element of the framework — aimed at improving categorical differentiationwould involve introducing a tiered approach to developing countries' mitigation efforts. This could be achieved by adding one or more new Annexes under the convention or the new agreement, although creating further subcategories within the non-Annex I group may be easier to reconcile with developing countries' concern for maintaining differential treatment.

Membership in each category should be based on objective criteria, such as per capita income or emissions. This would imply, among other things, that the wealthiest non-Annex I countries could be deemed candidates for joining Annex I. In order to enable rapidly industrializing developing economies to take on binding commitments commensurable with their circumstances, certain categories would entail intermediate forms of mitigation commitment, such as targets to reduce emissions compared to a business-as-usual projection or to reduce the emissions intensity of national production. To ensure predictability in tracking global emissions trends, all developing economies with high aggregate emissions (such as the BASIC countries) could be required to comply with stringent emissions monitoring standards. This would be compatible with national differentiation under which countries with much lower per capita emissions and income (such as India) had less demanding targets than those with higher per 29 
capita income and emissions (such as the other BASIC countries). Positive incentives for adopting the approach—such as eligibility to receive financial support or to participate in international emissions trading mechanisms—could be attached to membership in particular categories.

The second element of the framework would involve the progressive incorporation of principles for national differentiation within and across country categories. National differentiation could be guided at a broad level by a shared long-term goal, such as convergence to roughly equal per capita emissions by 2050 , with countries adopting steeper convergence trajectories as they graduate to more stringent categories of commitment. A tiered approach may help to make agreement on effort-sharing principles somewhat more tractable, since formulabased allocation methods will initially apply most stringently to a limited range of countries that have met certain threshold criteria. Even so, for the reasons we have outlined above, agreement on substantive principles will be challenging. We therefore outline further transitional steps that may be required.

An initial step would involve strengthening existing avenues for facilitating deliberation on effort-sharing principles within and outside the UNFCCC. ${ }^{61}$ This could include: quantitative comparison of the effectiveness, costs, and distributive implications of different effort-sharing options in the next assessment report of the IPCC (due for staged release in 2013-2014); further official workshops on effort-sharing hosted by the UNFCCC; and regular publication of nongovernmental indices that can "name and shame" laggards while giving credit to those that

${ }^{61}$ Compare John S. Dryzek and Hayley Stevenson, “Global Democracy and Earth System Governance,” Ecological Economics 70, no. 11 (2011). 
have made stronger pledges. A further transitional step would be to integrate deliberation on criteria into the process of formulating national targets well before the long-term agreement commences. For example, as part of the current process of "clarifying" existing mitigation pledges and possible measures to update pre-2020 pledges, each party could be required to report the criteria it has used to select its level of mitigation (similar to the way in which each developed country must justify the sense in which its climate finance contribution is "new and additional"). ${ }^{62}$ While this alone would not ensure that the resulting commitment reflects widely accepted principles, the transparency thereby achieved would raise the reputational costs to parties that base their commitments on self-serving grounds.

Having sketched the elements of the institutional framework, we must answer the critical question of whether it (or indeed any comparable framework) can satisfy all the constraints we have set out. A key advantage of our framework is that the two types of improved differentiation provide the basis for a principled bargain between developed and developing countries. Achieving such a bargain would require significant compromises but yield substantial gains on both sides. On the one hand, the calls by developed countries for more robust developing country participation can be satisfied if developing countries agree to the reform of categorical differentiation. On the other hand, recognition of developing countries' special circumstances and wealthy countries' responsibility to lead (which are necessary for satisfying basis for differentiation) can be achieved if developed countries and some developing countries compromise on their resistance to principled approaches to national differentiation (which would

\footnotetext{
${ }^{62}$ UNFCCC, "Outcome of the Work of the Ad Hoc Working Group on Long-Term Cooperative Action under the Convention,” Decision 2/CP.17, 17th Conference of the Parties to the UNFCCC, Durban, 2011 (2012), paras. 5 and 34
} 
then provide a foundation for satisfying fairness). Working within a reformed Annex system would help to ensure institutional compatibility. By addressing core concerns of each negotiating group, the elements of the bargain taken together would help to ensure perceived fairness.

Perhaps the most difficult outstanding question is whether all these constraints could be met while simultaneously ensuring effectiveness at reasonable costs. A precise answer to this question would require quantitative modeling of effort-sharing arrangements, which is beyond the scope of this article. However, some findings from existing research may help shed light on the question. While numerous quantitative models find that stabilization at 2 degrees Celsius remains physically and technically feasible despite recent high emissions, the task becomes considerably more challenging once constraints relating to cost, equity, and incomplete participation are incorporated. ${ }^{63}$ Under tight constraints—such as full historical responsibility and delayed participation of developing countries until 2030—stabilization at 2 degrees Celsius becomes infeasible under many models. ${ }^{64}$

Since our framework is compatible with limited recognition of historical responsibility and allows only limited delay in the participation of major developing countries, its degree of feasibility would lie somewhere between scenarios based purely on securing environmental effectiveness and those with tight constraints. Some analysis suggests that limited delay can

\footnotetext{
${ }^{63}$ Joeri Rogelj et al., "Emission Pathways Consistent with a $2{ }^{\circ} \mathrm{C}$ Global Temperature Limit," Nature Climate Change 1, no. 8 (2011).

${ }^{64}$ Massimo Tavoni, Shoibal Chakravarty, and Robert Socolow, "Safe vs. Fair: A Formidable Trade-off in Tackling Climate Change," Sustainability 4, no. 2 (2012); and Leon Clarke et al., "International Climate Policy Architectures: Overview of the EMF 22 International Scenarios," Energy Economics 31, supp. 2 (2009).
} 
substantially reduce overall costs compared to delay until $2030 .{ }^{65}$ Other research has modeled frameworks that bear substantial similarities to our own, where a progressively wider range of countries is incorporated into a "staged" system of commitments over time. Among the bestknown examples of this type are the South-North Dialogue proposal and Multi-Stage Convergence. ${ }^{66}$ Recent modeling of some of these proposals suggests that most of the constraints outlined above could be fulfilled, although the Multi-Stage proposal would likely yield warming of around 2 degrees Celsius at relatively high cost, while Bosetti and Frankel estimate their proposal would yield warming of 2.8 degrees Celsius, albeit at lower cost. ${ }^{67}$ Further analysissome of which will be undertaken as part of the next IPCC assessment report-is required to enable comparative evaluation of these models and where necessary lead to the development of alternative models. However, the available analysis suggests that a framework fulfilling the constraints we have outlined cannot be dismissed out of hand as infeasible.

\section{CONCLUSION}

We have argued that despite continuing contestation over the meaning of equity, considerations of fairness are not fundamentally incompatible with reaching an effective global climate agreement. At the center of our proposal for fair differentiation is a principled bargain between developed and developing countries involving the moderation of categorical differentiation in

\footnotetext{
${ }^{65}$ Peter Russ and Tom van Ierland, "Insights on Different Participation Schemes to Meet Climate Goals,” Energy Economics 31, supp. 2 (2009).

${ }^{66}$ Winkler, Brouns, and Kartha, "Future Mitigation Commitments"; and Michel den Elzen et al., "Multi-Stage: A Rule-Based Evolution of Future Commitments under the Climate Change Convention," International Environmental Agreements: Politics, Law and Economics 6, no. 1 (2006).

${ }^{67}$ Tommi Ekholm et al., "Effort Sharing in Ambitious, Global Climate Change Mitigation Scenarios," Energy Policy 38, no. 4 (2010); and Bosetti and Frankel, "Politically Feasible Emissions Targets," p.105.
} 
exchange for a more principled approach to national differentiation. In taking this approach we have aimed to illustrate not only how negotiations can (and should) take fairness into account but also how policy-oriented research in climate ethics can (and should) pay more systematic attention to feasibility considerations.

What gives us reason to think that a more principled approach could work in future when other past efforts have failed? Arguably, the key catalyst is that an effective global climate agreement now urgently requires mitigation within all large economies, which will in turn require an agreement that is perceived as fair by developing as well as developed countries. The bargain we have sketched here would help ensure that even if large and advanced developing economies participate in an agreement on a similar legal footing to developed countries, the scope of their commitments would continue to reflect important differences in their per capita emissions and income compared to wealthy countries.

The challenge of arriving at such a bargain cannot be underestimated. It is vulnerable not least to the risk that the United States may refuse to participate in an agreement even if its participation demand is met. In that case prospects for effective global action would depend more on such factors as domestic advocacy on climate change within the United States, possibly trade measures initiated by participants in the agreement, and non-climate drivers, such as competition for clean energy markets and energy security concerns. An even greater risk is that if ambitious global mitigation efforts are delayed beyond 2020, whatever opportunities remain to avoid dangerous climate change without sacrificing fairness will rapidly diminish. Still, it is too soon to concede the impossibility of an agreement that is both effective and fair. Indeed, the chances of securing the necessary degree of participation may ultimately be greatest where 
equity - appropriately conceived—is not left out of the framework but rather built into its foundations. 